\title{
Comparison of structural allograft and traditional autograft technique in occipitocervical fusion: radiological and clinical outcomes from a single institution
}

\author{
*Jakub Godzik, MD, ${ }^{1}$ Vijay M. Ravindra, MD, ${ }^{2}$ Wilson Z. Ray, MD, ${ }^{1}$ Meic H. Schmidt, MD, MBA, ${ }^{2}$ \\ Erica F. Bisson, MD, MPH, ${ }^{2}$ and Andrew T. Dailey, MD² \\ 'Department of Neurosurgery, Washington University, St. Louis, Missouri; and 2Department of Neurosurgery, Clinical \\ Neurosciences Center, University of Utah, Salt Lake City, Utah
}

\begin{abstract}
OBJECT The authors' objectives were to compare the rate of fusion after occipitoatlantoaxial arthrodesis using structural allograft with the fusion rate from using autograft, to evaluate correction of radiographic parameters, and to describe symptom relief with each graft technique.

METHODS The authors assessed radiological fusion at 6 and 12 months after surgery and obtained radiographic measurements of C1-2 and C2-7 lordotic angles, C2-7 sagittal vertical alignments, and posterior occipitocervical angles at preoperative, postoperative, and final follow-up examinations. Demographic data, intraoperative details, adverse events, and functional outcomes were collected from hospitalization records. Radiological fusion was defined as the presence of bone trabeculation and no movement between the graft and the occiput or C-2 on routine flexion-extension cervical radiographs. Radiographic measurements were obtained from lateral standing radiographs with patients in the neutral position.
\end{abstract}

RESULTS At the University of Utah, 28 adult patients underwent occipitoatlantoaxial arthrodesis between 2003 and 2010 using bicortical allograft, and 11 patients were treated using iliac crest autograft. Mean follow-up for all patients was 20 months (range 1-108 months). Of the 27 patients with a minimum of 12 months of follow-up, 18 (95\%) of 19 in the allograft group and $8(100 \%)$ of 8 in the autograft group demonstrated evidence of bony fusion shown by imaging. Patients in both groups demonstrated minimal deterioration of sagittal vertical alignment at final follow-up. Operative times were comparable, but patients undergoing occipitocervical fusion with autograft demonstrated greater blood loss ( $316 \mathrm{ml} v \mathrm{vs}$ $195 \mathrm{ml})$. One (9\%) of 11 patients suffered a significant complication related to autograft harvesting.

CONCLUSIONS The use of allograft in occipitocervical fusion allows a high rate of successful arthrodesis yet avoids the potentially significant morbidity and pain associated with autograft harvesting. The safety and effectiveness profile is comparable with previously published rates for posterior $\mathrm{C} 1-2$ fusion using allograft.

http://thejns.org/doi/abs/10.3171/2014.12.SPINE14535

KEY WORDS autograft; allograft; occipitocervical fusion; sagittal vertical alignment; posterior occipitocervical angle; cervical

$\mathrm{O}$ CCIPITOCERVICAL fusion (OCF) can be used to correct joint instability caused by trauma, rheumatological conditions, infection, neoplasm, or congenital conditions. ${ }^{10}$ Although nonrigid constructs have been used in OCF, rigid fixation involving screws with plate or rods in conjunction with sublaminar wiring and bone grafting is biomechanically superior to external im- mobilization. ${ }^{13,17,29,45}$ Although autograft provides the ideal substrate for bony fusion after posterior cervical arthrodesis, the associated rate of significant donor-site morbidity remains a concern. ${ }^{6,37}$ Autograft harvesting has also been associated with increased operative times, greater blood loss, ambulation difficulties, and chronic donor-site pain. ${ }^{9,25}$

ABBREVIATIONS NDI = Neck Disability Index; OCF = occipitocervical fusion; RA = rheumatoid arthritis; SVA = sagittal vertical alignment.

SUBMITTED May 30, 2014. ACCEPTED December 3, 2014.

INCLUDE WHEN CITING Published online May 8, 2015; DOI: 10.3171/2014.12.SPINE14535.

DISCLOSURE This project was supported by the Clinical and Translational Science Award (CTSA) program of the National Center for Advancing Translational Sciences

(NCATS) of the National Institutes of Health (NIH) under Award Number TL1 TR000449.

* Drs. Godzik and Ravindra contributed equally to this work. 
The use of cadaveric structural allograft for bone grafting reliably provides high rates of bony fusion and low rates of associated morbidity. ${ }^{3,22,35}$ Although the utility of structural allograft has been demonstrated in anterior cervical discectomy and fusion and in posterior atlantoaxial fixation, ${ }^{16,45}$ there are limited data about its use in rigid internal fixation constructs for OCF.

To enhance the fusion rates of posterior cervical fusion constructs, our graft placement and cabling technique is designed to generate additional compressive loading. To our knowledge, the use of interpositional structural allograft in OCF has not been assessed in clinical studies. In the present study, we investigated fusion rates, complications, radiographic evidence of correction, and subjective outcomes in 39 patients who underwent OCF using either autograft or structural allograft at the University of Utah Hospital. We hypothesized that the rate of fusion would be comparable between graft types and that the allograft cohort would experience decreased morbidity.

\section{Methods \\ Patient Population}

With institutional review board approval, we identified all single-stage OCF procedures performed at a single institution on adult patients ( $>18$ years old) between 2003 and 2010. Patients who received recombinant human bone morphogenetic protein-2 were excluded from this study. With this exception, all patients in this cohort were eligible for inclusion.

All data regarding patients' hospitalization, including clinic chart data, outcome instruments, and any correspondence, were reviewed. We recorded age at surgery, indications, number of prior surgeries (1 or many), and medical comorbidities. Intraoperative details included graft type, fusion length, duration of surgery, and estimated blood loss. Adverse events that occurred before the final followup were noted. Functional outcomes were assessed by comparison of pre- and postoperative values of the verbal numerical rating scale of neck pain, ${ }^{24}$ neurological status, Neck Disability Index (NDI), ${ }^{43}$ and Ranawat score. ${ }^{32}$ Outcome measures are reported based on each patient's status at his or her last follow-up.

\section{Operative Technique and Bone Grafting}

Instrumentation was performed as described by $\mathrm{Lu}$ et al. ${ }^{21}$ We placed C-1 lateral mass screws, which were typically 3.5 or $4.0 \mathrm{~mm}$ in diameter and $28-34 \mathrm{~mm}$ in length, and C-2 pedicle screws, which were 3.5 or $4.0 \mathrm{~mm}$ in diameter and $22-28 \mathrm{~mm}$ in length. Occipital screws ranged from 3.5 to $4.5 \mathrm{~mm}$ in diameter and were $6-14 \mathrm{~mm}$ in length. Occipital screws were placed within $1 \mathrm{~cm}$ of the midline just caudal to the inion. Rigid fixation was achieved using a fixed occipital plate and in conjunction with C-1 lateral mass screws and C-2 pedicle screws connected by a titanium fixation rod. ${ }^{28}$ After the hardware was in place, an interpositional graft was contoured to maximize contact between the surfaces of the decorticated occiput and axis. Autograft was harvested from the posterior iliac crest as detailed by Myeroff and Archdeacon. ${ }^{27}$ All allograft specimens were cadaveric bicortical iliac crest provided by the Musculoskeletal Transplant Foundation in standard $3 \times 3.5-\mathrm{cm}$ sizes, cleaned and sterilized by a proprietary processing method designed to preserve the osteoconductive properties of the graft material. We decorticated the entire exposed bony surface of the occiput and the rostral axis lamina and the spinous process with a high-speed bur drill. The graft was notched to closely align with the spinous process of the axis (Fig. 1 left) and was wedged against the decorticated surface of the occiput (Fig. 1 right). Cabling techniques varied depending on the amount of bone present, specifically the integrity of the arch of C-1, for anchoring. We used the Songer titanium cable (Medtronic Sofamor Danek) to secure the graft to the bony surfaces of the occiput and the axis. One of 2 methods was used, depending on the amount of bone present: 1) if the arch of C-1 was intact, a hole was placed through the graft, and the cable was looped through the graft and around the arch of C-1 (Fig. 2); or 2) if the arch of C-1 had been removed, which was the case in a majority of the patients, the cable was looped around the rod construct at C-1 and was tightened (Fig. 3). When the cable was tightened around the graft and rods, compressive loading was spread across both the occipital and axis bony surfaces.., 16

\section{Assessment of Fusion}

Radiological fusion was defined as the presence of bone trabeculation without evidence of loosening or breakage of instrumentation and no observed motion between the graft and either the occiput or the C-2 spinous process. ${ }^{19}$ Fusion was measured both as time to event and categorical status (fused or nonfused). We reviewed routine flexion-extension cervical radiographs obtained at 6- and 12-month intervals. Additional follow-up CT scans were used in the event of an inconclusive radiographs ${ }^{19}$ because the combination of $\mathrm{CT}$ and dynamic radiography predicts fusion rates with almost $90 \%$ accuracy according to experimental studies. ${ }^{38}$

\section{Radiographic Measurements}

Radiographic measurements at preoperative, postoperative, and final follow-up time points were obtained from the lateral standing radiographs with patients in the neutral position. The following spinal parameters were evaluated and are shown in Fig. 4: 1) C1-2 lordotic angle; 2) C2-7 lordotic angle; 3) C2-7 sagittal vertical alignment (SVA) (deviation of the C-2 plumb line from the posterior superior endplate of C-7); and 4) posterior occipitocervical angle (angle between the tangent of the occipital base and the posterior aspect of the C-3 and C-4 facet joints). ${ }^{14,15,33}$ Patients with $<12$ months of follow-up were excluded from analysis.

\section{Statistical Analysis}

Statistical analysis of continuous and dichotomous variables was conducted using the Mann-Whitney U-test and Fisher's exact test, respectively. Bivariate analysis of paired data was performed using the Wilcoxon signedrank test of nonparametric data. Kaplan-Meier survival analysis and the log-rank test were used to compare time 

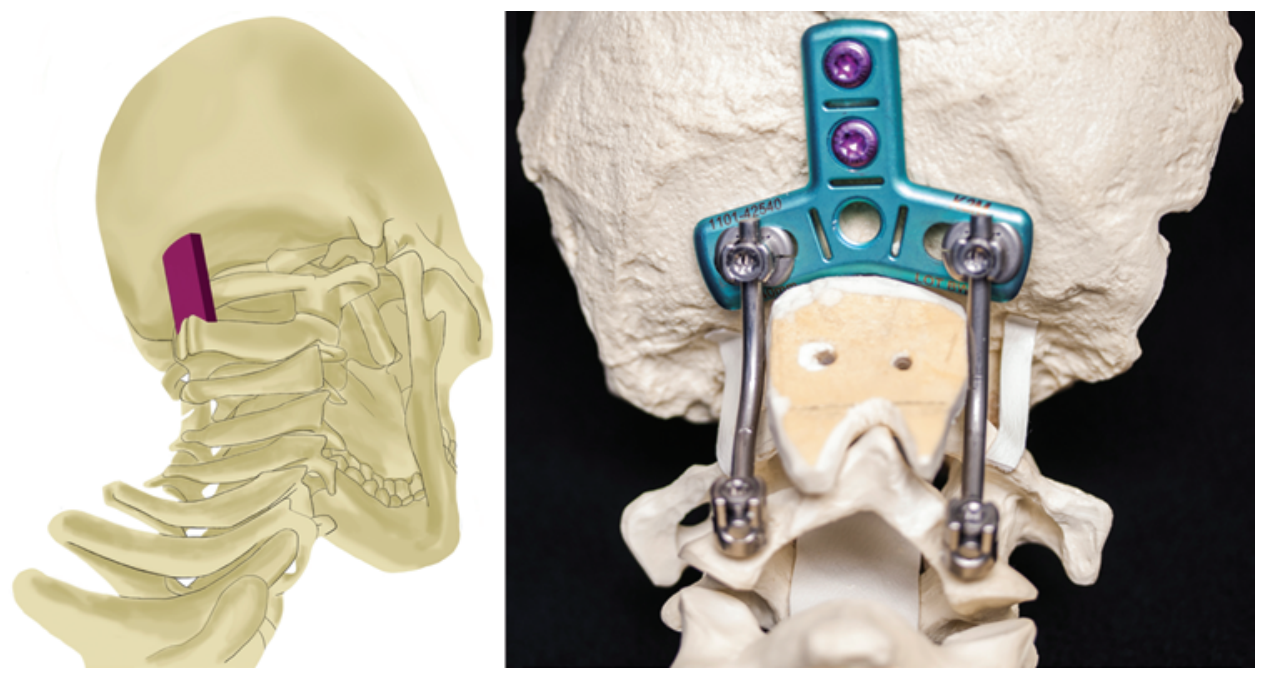

FIG. 1. Left: 3D illustration demonstrating the interpositional relationship of the graft material between the occiput and C-2. Copyright Department of Neurosurgery, University of Utah. Published with permission. Right: Photograph depicting the contouring and fit of the graft material in the construct; note that the notches of the graft fit atop and alongside the spinous process of $\mathrm{C}-2$ (hardware courtesy of K2M). Figure is available in color online only.

to fusion between the 2 graft types. All analyses were performed using SPSS V.21 (IBM). Statistical significance was defined as $\mathrm{p}<0.05$.

\section{Results}

Forty-four consecutive patients underwent single-stage rigid posterior OCF between 2003 and 2010. Five patients were excluded because recombinant human bone morphogenetic protein-2 was used. Of the remaining 39 patients, 28 underwent $\mathrm{OCF}$ with allograft, and 11 underwent $\mathrm{OCF}$ with autograft (Table 1). A total of 19 patients with allograft (19 of 28,68\%) and 8 patients with autograft (8 of $11,73 \%$ ) had follow-up of 12 months or more.

\section{Baseline Characteristics}

The mean age of patients was 45.3 years (range 21-68

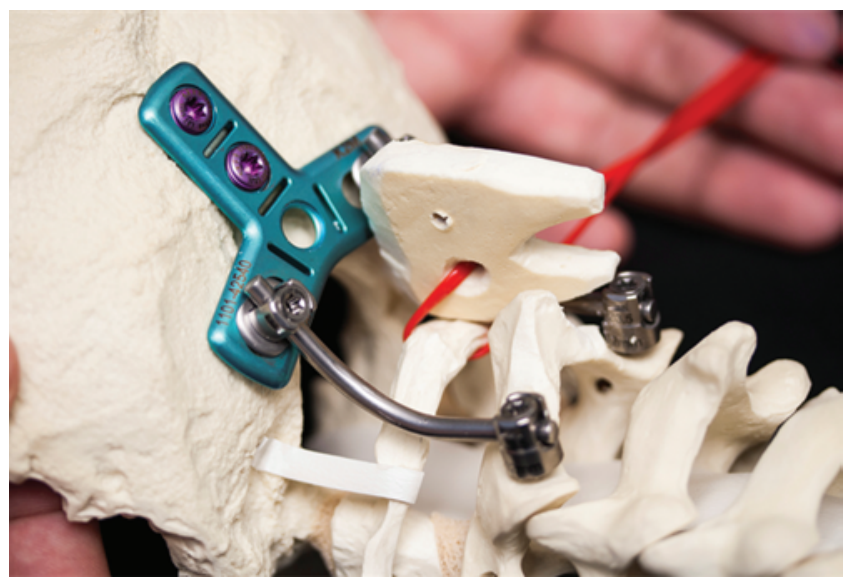

FIG. 2. Photograph showing graft material with construct. The loop of red cable represents the Songer cable. This image depicts the technique of looping the Songer cable around the intact arch of C-1 and opposing the forces of the graft to native bone surfaces with the graft elevated. Figure is available in color online only. years) in the autograft group and 49.7 years (range 18-82 years $)$ in the allograft group $(\mathrm{p}=0.590)$. Operative indications differed in the 2 groups (Table 1): Neoplasm (6 of $11,54 \%)$ and trauma $(2$ of $11,18 \%)$ predominated in the autograft group, whereas rheumatoid arthritis (RA) (7 of $28,25 \%$ ) was most common in the allograft group. The mean follow-up was similar in the 2 groups ( $\mathrm{p}=0.548$ ).

The mean time from symptom onset to surgery was also similar (autograft 13 months; allograft 12.4 months; $p=0.396)$. Forty-five percent of patients (5 of 11) in the autograft group had previous cervical spine surgery, compared with $28 \%$ ( 8 of $28, p=0.234$ ) in the allograft group; the graft material used in earlier surgeries was autograft in 3 , allograft in 1 , and unknown in 7 . There was no history of occipitocervical instrumentation in either cohort. The number of levels fused was similar in the autograft and

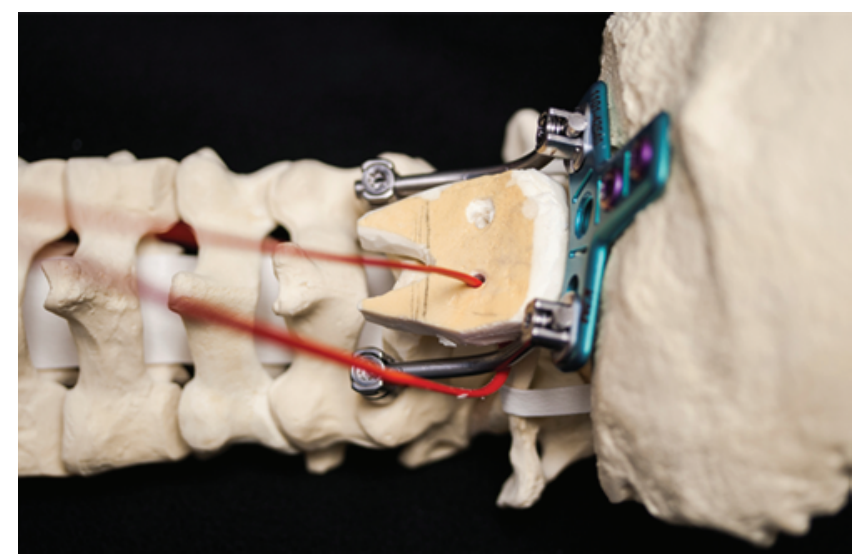

FIG. 3. Photograph showing graft material with the construct. The red loop represents the Songer cable. This image depicts the technique of looping the Songer cable around the rod construct to secure the graft in place. This technique may be used when $\mathrm{C}-1$ laminectomy has been performed. This configuration displays the graft in the position in which it will be fixed. Figure is available in color online only. 


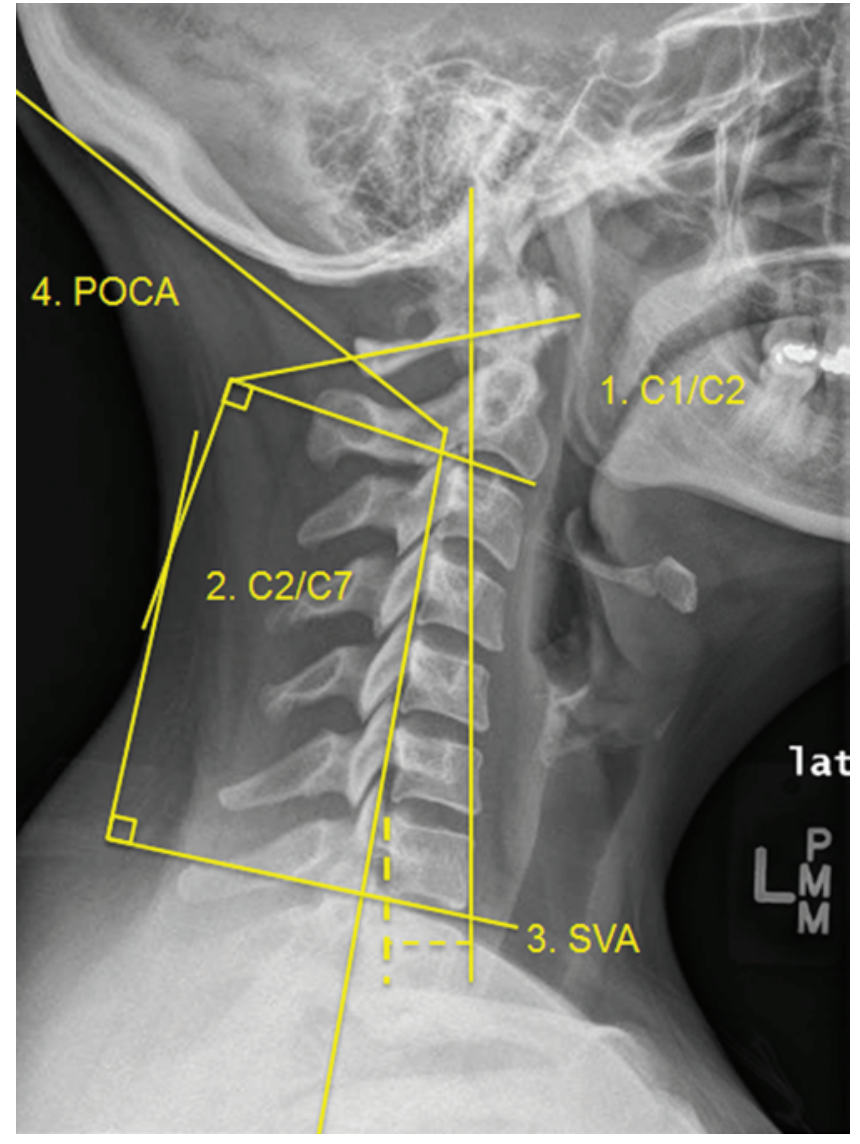

FIG. 4. Radiographic measurements on a lateral standing radiograph with the patient in the neutral position. The following spinal parameters were evaluated: 1) C1-2 lordotic angle; 2) C2-7 lordotic angle; 3) C2-7 SVA (deviation of the $\mathrm{C}-2$ plumb line from the posterior superior endplate of C-7); and 4) posterior occipitocervical angle (POCA, the angle between the tangent of the occipital base and the posterior aspect of the C-3 and C-4 facets). ${ }^{12,13,29}$ Figure is available in color online only.

allograft groups (mean 3.2 levels, range 2-5 levels, and mean 3.1 levels, range 2-9 levels, respectively; $p=0.414$ ).

One patient in the autograft group and 2 patients in the allograft group had a preoperative diagnosis of diabetes mellitus. One patient in the autograft group was receiving chronic steroid therapy for longstanding RA, and 11 patients in the allograft group were receiving either chronic steroid therapy or immune-modulating medication (e.g., etanercept, methotrexate) preoperatively, and 10 had a known diagnosis of RA or other autoimmune condition. Three (11\%) of 28 patients in the allograft group had a significant smoking history, whereas 2 (18\%) of 11 in the autograft group had a significant smoking history $(\mathrm{p}=$ $0.609)$. All patients for whom surgery was elective were advised to quit smoking, but 3 patients required urgent surgery and still admitted to smoking in the perioperative period.

\section{Surgical Characteristics}

Anesthesia and nursing records of the operations were available for all patients in the allograft group and for all except 1 in the autograft group. The mean operative time
TABLE 1. Comparison of patients who underwent occipitocervical fusion with allograft or autograft

\begin{tabular}{|c|c|c|c|}
\hline \multirow[b]{2}{*}{ Characteristics } & \multicolumn{2}{|c|}{ Group } & \multirow[b]{2}{*}{$\mathrm{p}$ Value } \\
\hline & $\begin{array}{l}\text { Allograft } \\
(n=28)\end{array}$ & $\begin{array}{l}\text { Autograft } \\
(n=11)\end{array}$ & \\
\hline Age in yrs (range) & $49.7(18-82)$ & $45.3(21-68)$ & 0.590 \\
\hline No. of female pts (\%) & $19(67)$ & $5(45)$ & 0.277 \\
\hline $\begin{array}{l}\text { No. of previous ops in all } \\
\text { pts }(\%)\end{array}$ & $8(28)$ & $5(45)$ & 0.453 \\
\hline $\begin{array}{l}\text { Duration of symptoms in mos } \\
\text { (range) }\end{array}$ & $12.4(0-66)$ & $13(0-108)$ & 0.396 \\
\hline No. of levels fused (range) & $3.1(2-9)$ & $3.2(2-5)$ & 0.414 \\
\hline \multicolumn{4}{|l|}{ Indication, no. (\%) } \\
\hline RA & $7(25)$ & $1(9)$ & - \\
\hline Neoplasm & $3(10)$ & $6(54)$ & - \\
\hline Chronic traumatic injury & $6(21)$ & $1(9)$ & - \\
\hline Acute trauma & $6(21)$ & $2(18)$ & - \\
\hline Congenital disease & $6(21)$ & 0 & - \\
\hline $\begin{array}{l}\text { Mean follow-up in mos } \\
\quad \text { (range) }\end{array}$ & $23.7(1-108)$ & $35(1-108)$ & 0.548 \\
\hline
\end{tabular}

pts $=$ patients $;-=$ not applicable

was $284 \pm 93$ minutes for the autograft group and $243 \pm 73$ minutes in the allograft group ( $\mathrm{p}=0.281)$. In the 9 patients in the autograft group for whom estimated blood loss data were available, the mean loss was $316 \pm 187 \mathrm{ml}$, whereas in the 24 patients in the allograft group for whom estimated blood loss data were available, blood loss was 195 $\pm 89 \mathrm{ml}(\mathrm{p}=0.066)$.

\section{Complications}

The rate of graft site-related complications in the autograft group was 9\% (1 of 11), and hip fracture and persistent graft site pain required long-term pain management. In the allograft group, 3 patients had complications, including 1 case of postoperative airway swelling that required reintubation, 1 case of transient dysphagia, and 1 case of postoperative hematoma. No patients needed a delayed second-stage anterior decompression for progressive basilar invagination. During the follow-up period, no cases of instrumentation failure or screw pullout occurred in either group.

\section{Fusion Rates}

Radiographs were obtained in all patients, and additional CT scans were obtained if there was clinical concern about instability or if radiography was not thought to be adequate..$^{19,38}$ At the 6-month follow-up, imaging was available for 32 of 39 patients. Fusion was present in 11 (34\%) of 32 patients: 6 (27\%) of 22 in the allograft group versus $5(50 \%)$ of 10 in the autograft group $(\mathrm{p}=0.252)$. Eight patients treated with autograft had at least 12 months of follow-up, and all (8 of $8,100 \%)$ demonstrated solid bony fusion on flexion-extension radiographs (4 patients) or CT (4 patients). Of 19 patients treated with allograft who had at least 12 months of follow-up, 18 (95\%) demon- 
strated solid bony fusion on flexion-extension radiographs (8 patients, all fused) or CT scans (11 patients, 1 did not fuse) at final follow-up (100\% in the autograft group vs $95 \%$ in the allograft group, $\mathrm{p}=1.0$ ). Based on KaplanMeier analysis, the estimated median time to fusion was 8 months (range 5-13 months) in the autograft cohort and 10 months (range 5-31 months) in the allograft cohort ( $\mathrm{p}$ $=0.285$ ). The patient in whom fusion was not achieved underwent OCF for symptomatic basilar invagination and congenital C2-3 fusion; although plain flexion and extension radiographs demonstrated proper alignment at 12 and 24 months, follow-up CT imaging at 24 months failed to demonstrate complete fusion (Fig. 5).

\section{Radiographic Outcomes}

For all patients, the mean preoperative $\mathrm{C} 1-2$ lordotic angle was $35^{\circ}$ (range $22^{\circ}-53^{\circ}$ ), and the mean $\mathrm{C} 2-7$ lordotic angle was $16^{\circ}$ (range $-7^{\circ}$ to $50^{\circ}$ ); $\mathrm{C} 1-2$ lordosis accounted for $68 \%$ of total cervical lordosis (Table 2). The C2-7 SVA ranged from 7 to $61 \mathrm{~mm}$ (mean $25.5 \mathrm{~mm}$ ), and the mean preoperative posterior occipitocervical angle was $100^{\circ}$ (range $73^{\circ}-121^{\circ}$ ). There was no statistically significant difference in preoperative measurements between the 2 cohorts. Both groups demonstrated statistically significant yet comparable increases in C2-7 SVA between the immediate postoperative period and final follow-up

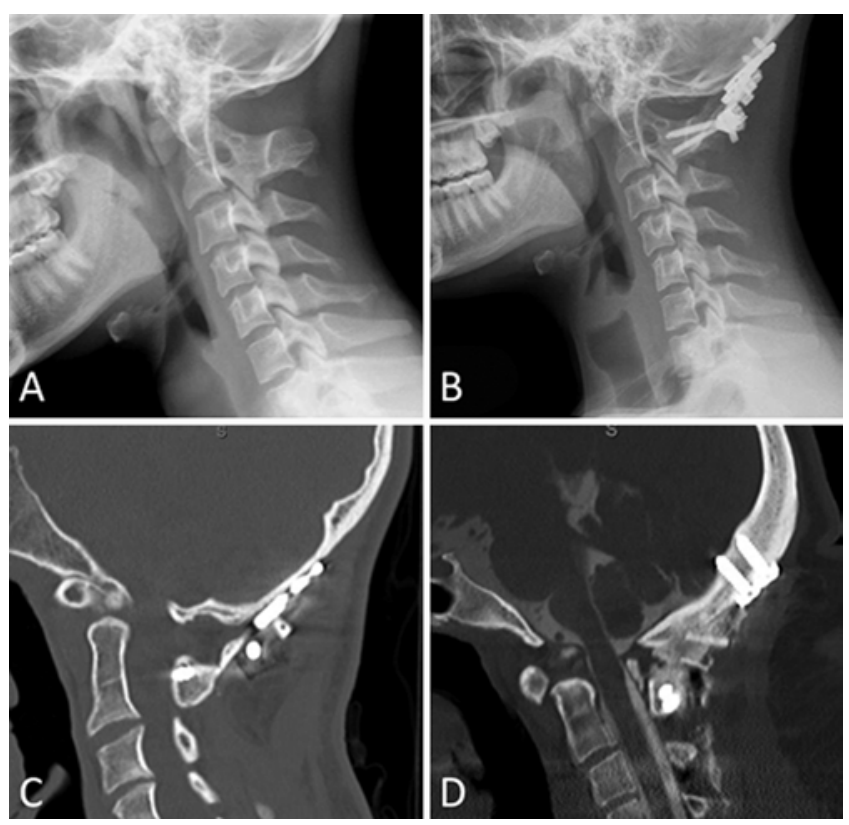

FIG. 5. A: Preoperative neutral plain radiograph of a 17-year-old patient with acute-onset weakness and occipital neuralgia secondary to basilar invagination and congenital fusion of $\mathrm{C} 2-3$ vertebrae. The patient underwent occiput-C2 fusion with bicortical iliac crest bone allograft and on postoperative examination reported relief of occipital neuralgia and myelopathy. B: The patient's basilar invagination and alignment remained improved on neutral plain radiography at a 24-month followup examination. C: CT scan at 24 months demonstrating bone graft incorporation at $\mathrm{C} 1-2$ but no evidence of definitive incorporation of graft into the occiput. D: In contrast, CT scan of a 30 -year-old patient after occiput-C2 fusion demonstrating evidence of definitive fusion across all levels at an 18-month follow-up examination.
TABLE 2. Comparison of radiographic data of 27 patients with a minimum of 12 months of follow-up

\begin{tabular}{|c|c|c|c|c|}
\hline Group \& Measurement & Preop & $\begin{array}{c}\text { Immediate } \\
\text { Postop }\end{array}$ & Postop & $p$ Value* \\
\hline \multicolumn{5}{|l|}{ Allograft $(n=19)$} \\
\hline \multicolumn{5}{|l|}{ Diagnostic measurements } \\
\hline $\mathrm{C} 1-2$ lordosis $\left(^{\circ}\right)$ & 36.4 & 31.1 & 32.1 & 0.228 \\
\hline C2-7 lordosis $\left(^{\circ}\right)$ & 15.2 & 16.1 & 15.0 & 0.541 \\
\hline C2-7 SVA (mm) & 27.3 & 27.5 & 32.2 & 0.005 \\
\hline $\operatorname{POCA}\left({ }^{\circ}\right)$ & 100.9 & 101.6 & 100.1 & 0.234 \\
\hline \multicolumn{5}{|l|}{ Autograft $(n=8)$} \\
\hline \multicolumn{5}{|l|}{ Diagnostic measurements } \\
\hline C1-2 lordosis $\left(^{\circ}\right)$ & 31.7 & 29.1 & 29.4 & 0.58 \\
\hline C2-7 lordosis $\left({ }^{\circ}\right)$ & 20.2 & 8.6 & 9.6 & 0.932 \\
\hline C2-7 SVA (mm) & 19 & 18.3 & 21.7 & 0.028 \\
\hline $\operatorname{POCA}\left({ }^{\circ}\right)$ & 100 & 105.7 & 104.9 & 0.344 \\
\hline
\end{tabular}

POCA = posterior occipitocervical angle.

* Difference between immediate postoperative imaging and final postoperative imaging according to Wilcoxon signed-rank test. Boldface indicates significance.

( $3.5 \mathrm{~mm}$ for autograft vs $4.4 \mathrm{~mm}$ for allograft, $\mathrm{p}=0.646$ ). Among all patients, the C2-7 SVA was correlated with C1-2 lordosis (Pearson's correlation $=0.583, p=0.004)$.

\section{Functional Outcomes}

The mean neck pain verbal numerical rating scale score improved significantly in both groups ( 7.3 to 3.3 for autograft, $\mathrm{p}=0.005 ; 5.9$ to 3.0 for allograft, $\mathrm{p}=0.011$ ). Seven of 8 patients $(87.5 \%)$ with 12 months of follow-up in the autograft group and 13 of 19 patients (68\%) with 12 months of follow-up in the allograft group had an improvement of more than 1 point $(\mathrm{p}=0.68)$. Of patients with preoperative neurological deficits, improvement occurred in 50\% (2 of 4) in the autograft group and in $92 \%$ (11 of 12) in the allograft group ( $\mathrm{p}=0.14)$. The mean NDI improved in both groups (54.6\% to $39 \%$ for autograft, $n$ $=3 ; 53 \%$ to $27 \%$ for allograft, $\mathrm{n}=5 ; \mathrm{p}=0.043$ ). The preoperative Ranawat score for the 1 patient with RA in the autograft group improved from Class II to Class I, and the median score in RA patients undergoing OCF with allograft improved from Class IIIA to a median post-OCF Class II $(\mathrm{n}=8, \mathrm{p}=0.1)$.

\section{Discussion}

Bicortical allograft may provide the same osteoconductive conduit for bony fusion as traditional autograft ${ }^{37}$ and may have comparable biomechanical properties,${ }^{34}$ and arthrodesis with allograft has been demonstrated in anterior cervical fusion ${ }^{25}$ and posterior C1-2 fusion. ${ }^{16}$ Allograft use in the posterior cervical spine has been associated with lower fusion rates that have been attributed to surgeons' inability to place the graft under compression. ${ }^{18,41}$ In our study, we described the use of structural interpositional grafts between the occiput and C-2 placed under compression, and we also compared radiographic outcomes at the 
12-month follow-up in these patients and outcomes in a cohort of patients in whom autografts were used for fusion.

We found that patients with symptomatic occipitoatlantoaxial instability could be safely and successfully treated with a 1-stage OCF with bicortical iliac allograft. After 12 months of follow-up, no difference $(p=1.0)$ in the fusion rates was observed between allograft and autograft patients, and at final follow-up $\geq 95 \%$ of patients in each group demonstrated bony fusion and minimal radiographic decompensation. We observed comparable improvement in subjective measures of neck pain between graft types but found a $9 \%$ rate of donor-site morbidity associated with harvesting of posterior iliac crest bone graft. In our study, this complication led to significant morbidity that included a hip fracture and prolonged stay in a skilled nursing facility; however, fusion with allograft resulted in a longer time to fusion as shown by Kaplan-Meier analysis and by findings from radiographs obtained at the 6-month follow-up. The clinical significance of these findings is unclear.

\section{Bone Grafting}

Stabilization of the mobile craniovertebral junction has historically presented a surgical challenge and has been associated with a high complication rates. The traditional source of graft material has been autologous bone, often harvested from the iliac crest or a rib during surgery. The autologous material provides an osteoconductive environment, along with osteoinductive properties that enhance new bone formation and promote osteogenic mesenchymal cell activities necessary for bone growth; however, the associated surgical-site morbidity rates and longer operative times compared with the use of allograft material are a source of concern.

The combined minor and major complication rate of donor-site morbidity has been reported to be as high as $49 \%$ in autologous iliac crest graft harvesting (Table 3). Dimitriou et al. ${ }^{6}$ reported a $19.37 \%$ rate of complications associated with iliac crest autografting in 6449 patients, and Sawin et al. ${ }^{37}$ reported a $25 \%$ rate of donor-site morbidity in a review of 600 posterior cervical cases. Donorsite chronic pain was observed in $17 \%$ at 3 months post- operatively ${ }^{6}$ rib grafting was associated with $3.7 \%$ rate of morbidity. ${ }^{37}$ Nockels et al. ${ }^{28}$ reported 1 case of donor-site infection in 24 patients who underwent autologous graft harvesting (4\%), and Grob et al. ${ }^{12}$ found a $3 \%$ incidence of infection in their patients. We found only 1 significant complication related to autograft harvesting (9\%) and a $14 \%$ incidence of perioperative complications in the allograft group. Because of the complex underlying pathology, this is a surprisingly low complication profile; as in previous studies of $\mathrm{OCF}$, the low rate of complications is likely a product of small sample size and retrospective study design. Additionally, our series indicated a reduction in blood loss between autograft and allograft groups of $121 \mathrm{ml}$ in favor of allograft procedures; however, the clinical significance of such differences in blood loss is unclear and may vary among diverse surgical populations.

The principal objection to using cadaveric bone allograft as a graft source has been the lack of osteoinductive factors that results from the sterilization process. ${ }^{37,44}$ Because of recent advances in sterilization and processing, allograft material may retain more osteoinductive properties and serve as a safe and effective adjunct to upper cervical fusion. In addition, allografts come in a variety of forms such as strips, cubes, wedges, and matrices that allow more versatile usage.

\section{Fusion Rates for Allograft Compared With Autograft}

Historically, the use of autografts has yielded superior rates of fusion in longer-length cervical constructs (those that involve $>1$ level) compared with allograft; allograft fusion has also been associated with more disc space collapse and angulation. Vaccaro et al..$^{41}$ noted that allograft used alone in neutral load was associated with slower incorporation and lower fusion rates compared to autologous bone graft; however, as Hillard et al. ${ }^{16}$ demonstrated, optimal placement of an allograft under compressive forces using rigid fixation provides a safe and effective adjunct to upper cervical fusion. We sought to replicate this technique of providing compressive forces by configuring the Songer cable to maximize the interpositional nature of the graft and the contact of the bony surfaces to promote ad-

TABLE 3. Comparison of indications and outcomes of various graft materials for OCF based on review of the literature

\begin{tabular}{|c|c|c|c|c|c|c|c|c|}
\hline Authors \& Year & $\begin{array}{l}\text { No. of } \\
\text { Cases }\end{array}$ & $\begin{array}{l}\text { No. w/ } \\
\text { Allograft }\end{array}$ & Graft Type & Diagnosis & $\begin{array}{l}\text { Instrument } \\
\text { Failure }\end{array}$ & $\begin{array}{l}\text { Fusion } \\
\text { Rate }\end{array}$ & $\begin{array}{c}\text { No. of Pts w/ } \\
\text { Donor-Site } \\
\text { Morbidity }\end{array}$ & $\begin{array}{c}\text { Rate of } \\
\text { Pain Relief }\end{array}$ \\
\hline Grob et al., 1999 & 39 & 0 & Autograft (ICBG) & RA & 0 & $84 \%$ & $1(3 \%)$ & $77 \%$ \\
\hline Sandhu et al., 2003 & 21 & 0 & Autograft (rib graft) & RA & 0 & $100 \%$ & NR & $71 \%$ \\
\hline Deutsch et al., 2005 & 58 & 0 & Autograft (ICBG) & Diverse & $5 \%$ & $94 \%$ & $5 \%$ & $86 \%$ \\
\hline Nockels et al., 2007 & 69 & 46 & Autograft or allograft & Diverse & $2.9 \%$ & $97 \%$ & $1 / 23(4 \%)$ & $75 \%$ \\
\hline Winegar et al., 2010 & 311 & 8 & $\begin{array}{l}\text { Allograft }(n=1) \text { or autograft + allograft } \\
\quad(n=7)\end{array}$ & Diverse & NR & $93 \%{ }^{*}$ & NR & $90 \%{ }^{*}$ \\
\hline Bhatia et al., 2013 & 100 & 100 & $\begin{array}{l}\text { Local autologous fragment + synthetic } \\
\text { bone }\end{array}$ & $\begin{array}{r}\text { RA, trauma, } \\
\text { neoplasm }\end{array}$ & $4 \%$ & $70 \%$ & NA & NR \\
\hline Present study & 44 & 28 & Allograft (ICBG) & $\begin{array}{r}\text { RA, trauma, } \\
\text { neoplasm }\end{array}$ & 0 & $95 \%$ & $1 / 11(9 \%)$ & $80 \%$ \\
\hline
\end{tabular}

ICBG = iliac crest bone graft; NA = not applicable; NR = not reported.

* Represents overall rate. 
equate fusion. More recently, fusion rates for single- and multilevel anterior cervical discectomy and fusion procedures have been reported to be as high as $90 \%-100 \%$ when using allograft, which improved postoperative morbidity, long-term patient outcomes, and cost effectiveness. ${ }^{1,16,25}$

Fusion rates after primary rigid posterior fixation for OCF have been reported to range between $70 \%$ and $100 \%$. ${ }^{2,12,20,28,36,42}$ High rates of fusion after OCF have been described, but few studies have compared fusion rates between different bone graft options (Table 3). ${ }^{8,45}$ These findings may be due, in part, to the historic precedent for the use of iliac bone crest autograft in this patient population. ${ }^{26}$ Among the studies that have examined fusion rates with materials other than autograft, Nockels et al. ${ }^{28}$ showed a $97 \%$ fusion rate in 69 patients who underwent OCF in which either autograft (33\%) or local autologous bone with allograft (67\%) was used and found no difference in outcomes between the groups. However, the authors noted the large volume of graft material required to span the length of the occiput-C2 fusion. In contrast, our series provides a head-to-head comparison of structural interpositional allograft versus autograft. Bhatia et al. ${ }^{2}$ reported their results for OCF in 100 patients in whom they placed autologous fragments with synthetic bone. Seventy percent of their patients demonstrated bony fusion, and 4\% suffered instrumentation failure within the follow-up period, which averaged 44 months. ${ }^{2}$ In the current study, however, we present the use of structural interpositional allograft with markedly greater fusion rates in comparison with those reported by Bhatia et al. ${ }^{2}$

Recently, Elliott et al. ${ }^{7}$ reviewed atlantoaxial grafting options and found no significant difference in fusion rates between allograft and autograft constructs but noted wide variability in the use of autograft, allograft, and bone morphogenetic protein. The study found a $99.7 \%$ fusion rate among 652 patients treated with autograft and a 100\% fusion rate among 60 patients treated with allograft in 7 studies; however, the majority of these included morselized allografts rather than the structural allograft described in the current study. The results of our series for OCF are similar, which suggests that patients who receive structural cadaveric iliac crest allograft can attain solid bony fusion at rates comparable with previously published rates associated with iliac crest bone autograft or local autologous graft material in atlantoaxial fusion.

Some authors argue that the evaluation of radiographic fusion should be treated as a time-dependent event using Kaplan-Meier survival analysis. ${ }^{40}$ Several groups have reported slower incorporation for allograft constructs, although the clinical significance of this observation remains unclear. ${ }^{41}$ Hillard et al. ${ }^{16}$ reported a single-center study comparison of autograft and allograft and reported that $50 \%$ of autografts and just $14 \%$ of allografts produced a fusion by 6 months; however, within a 12- to 24-month period both groups achieved high rates of fusion. In this study, we noted a trend toward longer fusion time in the allograft group-12.3 months compared with 8.2 months in the autograft group.

\section{Radiographic Outcomes}

Some authors suggest that postoperative radiographic alignment may be indicative of both construct longevity and subjective patient outcomes. ${ }^{23,26,28,30,39}$ Recently, Tang et al ${ }^{39}$ found a correlation between postoperative cervical alignment (C2-7 SVA) and quality-of-life outcome scores in 113 patients after cervical fusion procedures. In our series, we found that patients in both groups demonstrated improved cervical alignment after surgery. Although there was a small loss of cervical correction at the last followup, the significant improvement in these measurements in both groups suggests successful fusion, and these measurements may be predictors of long-term construct success and improved outcomes.

\section{Subjective Outcomes}

In their systematic review of outcomes in adult OCF, Winegar et al. ${ }^{45}$ reported a $90 \%$ rate of pain relief and a $73 \%$ rate of neurological improvement. Despite the heterogeneity of the patient population and surgical techniques, their study highlights the high rate of symptom relief that can be expected. In the largest study of subjective outcome measures in OCF patients, Bhatia et al. ${ }^{2}$ showed an improvement of NDI scores from $57.5 \%$ to $40 \%$ in 41 patients with RA. Likewise, we observed that patients treated with cadaveric bone allograft demonstrated an $80 \%$ reduction in neck pain and a decrease in NDI from 57\% to $30 \%$.

\section{Limitations}

This study has known limitations and biases relating to its retrospective design and small sample size. As with any retrospective study, data are limited by the accuracy and availability of medical records and appropriate duration of follow-up. Here, the mean follow-up ranged from 1 month to 4.5 years, and long-term subjective outcomes data (i.e., NDI scores) were available in only $25 \%$ of patients. For these reasons, patients were additionally evaluated for long-term changes in radiographic parameters, as well as pain and neurological function at final follow-up. The known heterogeneity of patients with cervical instability is a limitation in any study that evaluates a specific fusion technique for occipitoatlantoaxial instability. ${ }^{2}$ In the current study, the allograft group included 7 (25\%) of 28 patients with RA, and the autograft group included 6 (54\%) of 11 patients with neoplasm, which reflects possible selection bias and surgeon preference for grafting technique; however, in an effort to demonstrate the potential utility of structural allograft across diverse patient groups, we included all patients who underwent OCF at our institution.

Another limitation of the study is the number of patients lost to follow-up at 1 year-almost one-third of the patients. Two factors may account for this. First, many of our patients were trauma patients, and the orthopedic trauma literature notes that poor follow-up is a factor that negatively affects the trauma literature ${ }^{46}$ Second, many of our patients were elderly, or follow-up would have required long-distance travel, which limited the availability of follow-up radiographs.

In addition, some authors have questioned the utility of advanced imaging for radiographic assessment of fusion, emphasizing the primacy of clinical outcomes over radiographic verification. ${ }^{2,26}$ Kaiser et al. ${ }^{19}$ have recommended the use of dynamic imaging as a standard modality with 
the possible use of CT imaging to determine the extent of bone trabeculation. Published studies have reported similarly higher rates of nonfusion shown by $\mathrm{CT}$ imaging (10\%-31\%) compared with dynamic radiographic imaging $(2 \%-16 \%)$, as we did. ${ }^{31}$ Other authors have reported that a combination of $\mathrm{CT}$ and dynamic radiography yields the highest correlation with in vivo fusion. ${ }^{38}$ In our group, surgeons used this combination of modalities to assess fusion, and at least half of the patients in each group underwent $\mathrm{CT}$ to assess fusion status. Discrepancies among imaging methods may further complicate the comparison of fusion rates among studies, and the results should be interpreted carefully. ${ }^{11,31}$

\section{Conclusions}

This clinical series shows that patients who require surgery for symptomatic craniocervical instability can successfully undergo posterior OCF with the placement of rigid instrumentation and bicortical structural allograft. Because of the morbidities associated with autograft procurement in this high-risk population, the iliac crest structural allograft may serve as an alternative graft option for OCF patients because of the favorable fusion rates and comparable symptom relief. Furthermore, we suggest the use of CT evaluation to reliably discern the integrity of bony fusion after OCF in cases of clinical uncertainty.

\section{Acknowledgments}

We thank Kristin Kraus, MSc, for editorial assistance in preparing this paper, Vance Mortimer for his assistance with photography, and Ron I. Apfelbaum for his continued guidance and mentoring.

\section{References}

1. Balabhadra RS, Kim DH, Zhang HY: Anterior cervical fusion using dense cancellous allografts and dynamic plating. Neurosurgery 54:1405-1412, 2004

2. Bhatia R, Desouza RM, Bull J, Casey AT: Rigid occipitocervical fixation: indications, outcomes, and complications in the modern era. J Neurosurg Spine 18:333-339, 2013

3. Bishop RC, Moore KA, Hadley MN: Anterior cervical interbody fusion using autogeneic and allogeneic bone graft substrate: a prospective comparative analysis. J Neurosurg 85:206-210, 1996

4. Deutsch H, Haid RW Jr, Rodts GE Jr, Mummaneni PV: Occipitocervical fixation: long-term results. Spine (Phila Pa 1976) 30:530-535, 2005

5. Dickman CA, Sonntag VK, Papadopoulos SM, Hadley MN: The interspinous method of posterior atlantoaxial arthrodesis. J Neurosurg 74:190-198, 1991

6. Dimitriou R, Mataliotakis GI, Angoules AG, Kanakaris NK, Giannoudis PV: Complications following autologous bone graft harvesting from the iliac crest and using the RIA: a systematic review. Injury 42 (Suppl 2):S3-S15, 2011

7. Elliott RE, Tanweer O, Boah A, Smith ML, Frempong-Boadu A: Comparison of safety and stability of C-2 pars and pedicle screws for atlantoaxial fusion: meta-analysis and review of the literature. J Neurosurg Spine 17:577-593, 2012

8. Fargen KM, Anderson RC, Harter DH, Angevine PD, Coon VC, Brockmeyer DL, et al: Occipitocervicothoracic stabilization in pediatric patients. J Neurosurg Pediatr 8:57-62, 2011

9. Fernyhough JC, Schimandle JJ, Weigel MC, Edwards CC,
Levine AM: Chronic donor site pain complicating bone graft harvesting from the posterior iliac crest for spinal fusion. Spine (Phila Pa 1976) 17:1474-1480, 1992

10. Garrido BJ, Sasso RC: Occipitocervical fusion. Orthop Clin North Am 43:1-9, vii, 2012

11. Ghiselli G, Wharton N, Hipp JA, Wong DA, Jatana S: Prospective analysis of imaging prediction of pseudarthrosis after anterior cervical discectomy and fusion: computed tomography versus flexion-extension motion analysis with intraoperative correlation. Spine (Phila Pa 1976) 36:463-468, 2011

12. Grob D, Schütz U, Plötz G: Occipitocervical fusion in patients with rheumatoid arthritis. Clin Orthop Relat Res (366):46-53, 1999

13. Grubb MR, Currier BL, Stone J, Warden KE, An KN: Biomechanical evaluation of posterior cervical stabilization after a wide laminectomy. Spine (Phila Pa 1976) 22:1948-1954, 1997

14. Hardacker JW, Shuford RF, Capicotto PN, Pryor PW: Radiographic standing cervical segmental alignment in adult volunteers without neck symptoms. Spine (Phila Pa 1976) 22:1472-1480, 1997

15. Hilibrand AS, Tannenbaum DA, Graziano GP, Loder RT, Hensinger RN: The sagittal alignment of the cervical spine in adolescent idiopathic scoliosis. J Pediatr Orthop 15:627632,1995

16. Hillard VH, Fassett DR, Finn MA, Apfelbaum RI: Use of allograft bone for posterior C1-2 fusion. J Neurosurg Spine 11:396-401, 2009

17. Hurlbert RJ, Crawford NR, Choi WG, Dickman CA: A biomechanical evaluation of occipitocervical instrumentation: screw compared with wire fixation. J Neurosurg 90 (1 Suppl):84-90, 1999

18. Jorgenson SS, Lowe TG, France J, Sabin J: A prospective analysis of autograft versus allograft in posterolateral lumbar fusion in the same patient. A minimum of 1-year follow-up in 144 patients. Spine (Phila Pa 1976) 19:2048-2053, 1994

19. Kaiser MG, Mummaneni PV, Matz PG, Anderson PA, Groff MW, Heary RF, et al: Radiographic assessment of cervical subaxial fusion. J Neurosurg Spine 11:221-227, 2009

20. Lee SC, Chen JF, Lee ST: Clinical experience with rigid occipitocervical fusion in the management of traumatic upper cervical spinal instability. J Clin Neurosci 13:193-198, 2006

21. Lu DC, Roeser AC, Mummaneni VP, Mummaneni PV: Nuances of occipitocervical fixation. Neurosurgery 66 (3 Suppl):141-146, 2010

22. Malloy KM, Hilibrand AS: Autograft versus allograft in degenerative cervical disease. Clin Orthop Relat Res (394):27-38, 2002

23. Matsunaga S, Onishi T, Sakou T: Significance of occipitoaxial angle in subaxial lesion after occipitocervical fusion. Spine (Phila Pa 1976) 26:161-165, 2001

24. McCormack HM, Horne DJ, Heather S: Clinical applications of visual analogue scales: a critical review. Psychol Med 18:1007-1019, 1988

25. Miller LE, Block JE: Safety and effectiveness of bone allografts in anterior cervical discectomy and fusion surgery. Spine (Phila Pa 1976) 36:2045-2050, 2011

26. Moskovich R, Crockard HA, Shott S, Ransford AO: Occipitocervical stabilization for myelopathy in patients with rheumatoid arthritis. Implications of not bone-grafting. J Bone Joint Surg Am 82:349-365, 2000

27. Myeroff C, Archdeacon M: Autogenous bone graft: donor sites and techniques. J Bone Joint Surg Am 93:2227-2236, 2011

28. Nockels RP, Shaffrey CI, Kanter AS, Azeem S, York JE: Occipitocervical fusion with rigid internal fixation: long-term follow-up data in 69 patients. J Neurosurg Spine 7:117-123, 2007 
29. Oda I, Abumi K, Sell LC, Haggerty CJ, Cunningham BW, McAfee PC: Biomechanical evaluation of five different occipito-atlanto-axial fixation techniques. Spine (Phila Pa 1976) 24:2377-2382, 1999

30. Phillips FM, Phillips CS, Wetzel FT, Gelinas C: Occipitocervical neutral position. Possible surgical implications. Spine (Phila Pa 1976) 24:775-778, 1999

31. Ploumis A, Mehbod A, Garvey T, Gilbert T, Transfeldt E, Wood K: Prospective assessment of cervical fusion status: plain radiographs versus CT-scan. Acta Orthop Belg 72:342-346, 2006

32. Ranawat CS, O'Leary P, Pellicci P, Tsairis P, Marchisello P, Dorr L: Cervical spine fusion in rheumatoid arthritis. J Bone Joint Surg Am 61:1003-1010, 1979

33. Riel RU, Lee MC, Kirkpatrick JS: Measurement of a posterior occipitocervical fusion angle. J Spinal Disord Tech 23:27-29, 2010

34. Ryu SI, Lim JT, Kim SM, Paterno J, Willenberg R, Kim DH: Comparison of the biomechanical stability of dense cancellous allograft with tricortical iliac autograft and fibular allograft for cervical interbody fusion. Eur Spine J 15:1339_ 1345, 2006

35. Samartzis D, Shen FH, Matthews DK, Yoon ST, Goldberg EJ, An HS: Comparison of allograft to autograft in multilevel anterior cervical discectomy and fusion with rigid plate fixation. Spine J 3:451-459, 2003

36. Sandhu FA, Pait TG, Benzel E, Henderson FC: Occipitocervical fusion for rheumatoid arthritis using the inside-outside stabilization technique. Spine (Phila Pa 1976) 28:414-419, 2003

37. Sawin PD, Traynelis VC, Menezes AH: A comparative analysis of fusion rates and donor-site morbidity for autogeneic rib and iliac crest bone grafts in posterior cervical fusions. J Neurosurg 88:255-265, 1998

38. Sugiyama S, Wullschleger M, Wilson K, Williams R, Goss B: Reliability of clinical measurement for assessing spinal fusion: an experimental sheep study. Spine (Phila Pa 1976) 37:763-768, 2012

39. Tang JA, Scheer JK, Smith JS, Deviren V, Bess S, Hart RA, et al: The impact of standing regional cervical sagittal alignment on outcomes in posterior cervical fusion surgery. Neurosurgery 71:662-669, 2012
40. Tuli SK, Tuli J, Chen P, Woodard EJ: Fusion rate: a time-toevent phenomenon. J Neurosurg Spine 1:47-51, 2004

41. Vaccaro AR, Chiba K, Heller JG, Patel TC, Thalgott JS, Truumees E, et al: Bone grafting alternatives in spinal surgery. Spine J 2:206-215, 2002

42. Vale FL, Oliver M, Cahill DW: Rigid occipitocervical fusion. J Neurosurg 91 (2 Suppl):144-150, 1999

43. Vernon H, Mior S: The Neck Disability Index: a study of reliability and validity. J Manipulative Physiol Ther 14:409415, 1991

44. Wigfield CC, Nelson RJ: Nonautologous interbody fusion materials in cervical spine surgery: how strong is the evidence to justify their use? Spine (Phila Pa 1976) 26:687694, 2001

45. Winegar CD, Lawrence JP, Friel BC, Fernandez C, Hong J, Maltenfort M, et al: A systematic review of occipital cervical fusion: techniques and outcomes. J Neurosurg Spine 13:5-16, 2010

46. Zelle BA, Bhandari M, Sanchez AI, Probst C, Pape HC: Loss of follow-up in orthopaedic trauma: is $80 \%$ follow-up still acceptable? J Orthop Trauma 27:177-181, 2013

\section{Author Contributions}

Conception and design: Dailey, Ray. Acquisition of data: Godzik, Ravindra, Ray. Analysis and interpretation of data: Godzik, Ravindra, Ray. Drafting the article: Godzik, Ravindra, Ray. Critically revising the article: all authors. Reviewed submitted version of manuscript: all authors. Approved the final version of the manuscript on behalf of all authors: Dailey. Statistical analysis: Godzik, Ray. Study supervision: Dailey, Ray.

\section{Supplemental Information}

Previous Presentation

This research was presented at the 2014 AANS/CNS Joint Section on Disorders of the Spine and Peripheral Nerves.

\section{Correspondence}

Andrew T. Dailey, Department of Neurosurgery, Clinical Neurosciences Center, University of Utah, 175 N. Medical Dr. E, Salt Lake City, UT 84132. email: andrew.dailey@hsc.utah.edu. 